\section{(1) \\ CrossMark}

\title{
New insights in lymphangioleiomyomatosis and pulmonary Langerhans cell histiocytosis
}

\author{
Olga Torre, Davide Elia, Antonella Caminati and Sergio Harari
}

Affiliation: U.O. di Pneumologia e Terapia Semi-Intensiva Respiratoria, Servizio di Fisiopatologia Respiratoria ed Emodinamica Polmonare, Ospedale San Giuseppe, MultiMedica IRCCS, Milan, Italy.

Correspondence: Sergio Harari, U.O. di Pneumologia e Terapia Semi-Intensiva Respiratoria, Servizio di Fisiopatologia Respiratoria ed Emodinamica Polmonare, Ospedale San Giuseppe, MultiMedica IRCCS, via San Vittore 12, 20123 Milan, Italy. E-mail: sharariahotmail.it

@ERSpublications

Understanding of LAM/PLCH pathogenesis has improved over the past years, leading to new therapeutic approaches http://ow.ly/7wjR30erSJY

Cite this article as: Torre $\mathrm{O}$, Elia $\mathrm{D}$, Caminati $\mathrm{A}$, et al. New insights in lymphangioleiomyomatosis and pulmonary Langerhans cell histiocytosis. Eur Respir Rev 2017; 26: 170042 [https://doi.org/10.1183/ 16000617.0042-2017].

ABSTRACT Lymphangioleiomyomatosis (LAM) and pulmonary Langerhans cell histiocytosis (PLCH) are rare diseases that lead to progressive cystic destruction of the lungs. Despite their distinctive characteristics, these diseases share several features. Patients affected by LAM or PLCH have similar radiological cystic patterns, a similar age of onset, and the possibility of extrapulmonary involvement. In this review, the recent advances in the understanding of the molecular pathogenesis, as well as the current and most promising biomarkers and therapeutic approaches, are described.

\section{Introduction}

Lymphangioleiomyomatosis (LAM) and pulmonary Langerhans cell histiocytosis (PLCH) are rare diseases characterised by the presence of pulmonary parenchymal cysts (figure 1). Despite their distinctive characteristics, they both share several features: in addition to the cystic computed tomography (CT) scan pattern, these two diseases affect young adults more frequently and can show extrapulmonary involvement. Recent findings have transformed our understanding of these diseases and, as a result, LAM and PLCH are now classified as neoplastic diseases, according to the recent classification of diffuse cystic lung diseases [1].

\section{Lymphangioleiomyomatosis}

What is LAM?

LAM is a rare disease affecting predominantly women of childbearing age. It is characterised by cystic destruction of the lungs, lymphatic manifestations including lymphangioleiomyomas, and abdominal tumours known as angiomyolipomas, which usually affect the kidneys [2]. The disease can be sporadic or associated with the tuberous sclerosis complex (TSC), an autosomal dominant syndrome characterised by cerebral calcifications, mental retardation, seizures, and hamartomatous lesions in several organs $[3,4]$. LAM is caused by mutations in the tuberous sclerosis gene TSC1 and, in most cases, the TSC2 gene, with consequent loss of function of their protein products hamartin and tuberin, respectively [5-7]. The major

Received: April 032017 | Accepted after revision: July 262017

Conflict of interest: Disclosures can be found alongside this article at err.ersjournals.com

Provenance: Publication of this peer-reviewed article was sponsored by Boehringer Ingelheim Pharma GmbH \& Co. KG, Ingelheim am Rhein, Germany (principal sponsor, European Respiratory Review issue 145).

Copyright OERS 2017. ERR articles are open access and distributed under the terms of the Creative Commons Attribution Non-Commercial Licence 4.0. 

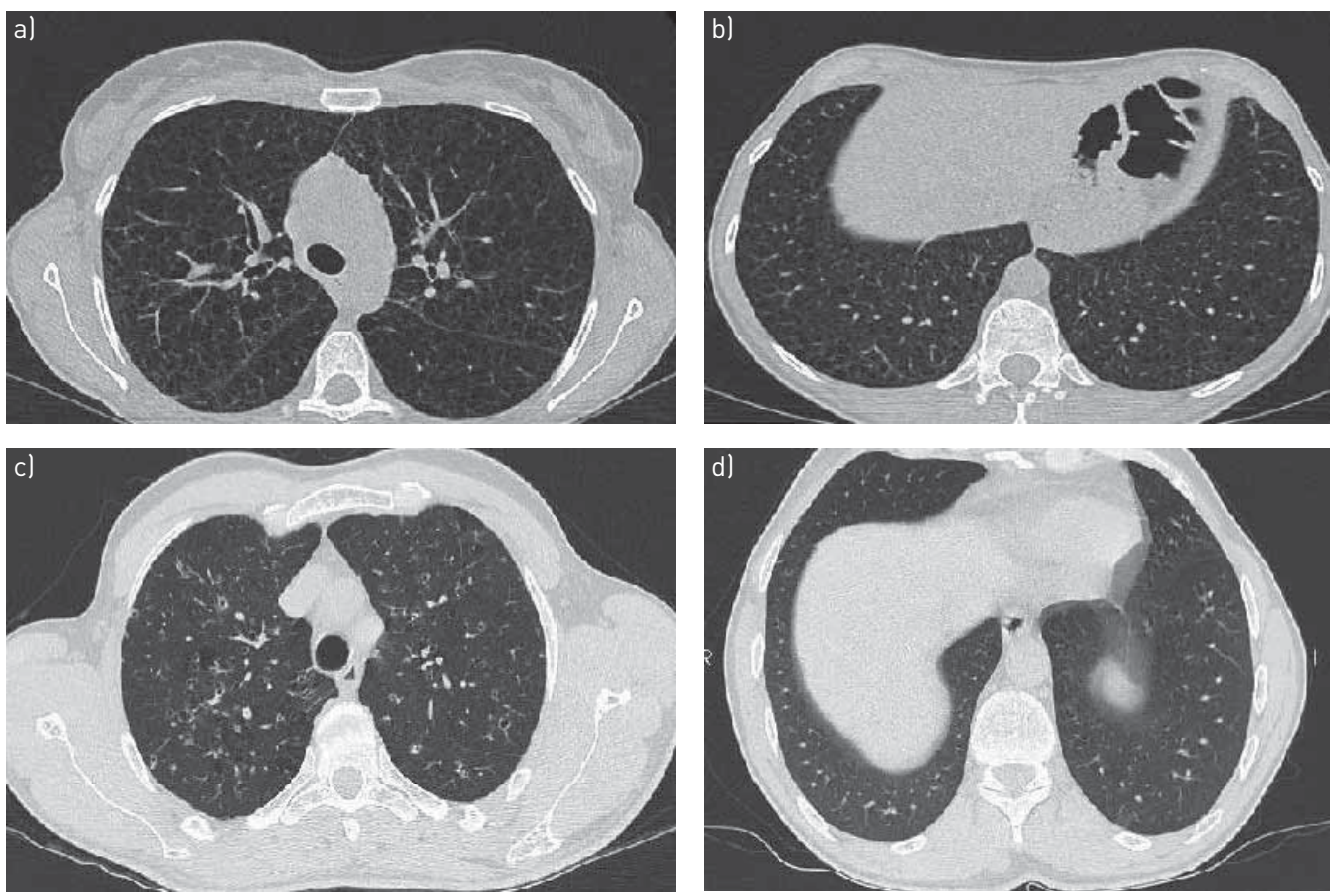

FIGURE 1 High-resolution chest computed tomography images of a patient with lymphangioleiomyomatosis showing round-shaped, thin-walled cysts distributed diffusely throughout the lungs without sparing of lung bases $(a, b)$, and a patient with pulmonary Langerhans cell histiocytosis with evidence of micronodules and cystic lesions mainly involving middle and upper lung fields (c, d).

role of the hamartin/tuberin heterotrimer is inhibition (mediated through the Ras homologue enriched in brain (Rheb)) of the mammalian/mechanistic target of rapamycin (mTOR), which is an intracellular kinase that serves as the central regulator of cell growth and proliferation [8-10]. In sporadic or TSC-associated LAM, inactivating mutations of TSC1 and TSC2 genes result in constitutive activation of the mTOR pathway.

LAM lesions are characterised by the presence of LAM cells, which include two types of subpopulations: small spindle-shaped cells expressing smooth muscle-specific proteins, such as $\alpha$-actin, vimentin and desmin; and epithelioid-like cells expressing markers of melanoma cells and immature melanocytes, such as gp100 and MelanA/Mart1 [11, 12]. In fact, LAM has been included in the family of "perivascular epithelioid cell tumours", a heterogeneous group of mesenchymal tumours composed of histologically and immunohistochemically distinctive perivascular epithelioid cells that typically coexpress myogenic and melanocytic markers [13]. Furthermore, several genetic and cellular findings support the neoplastic nature of LAM cells. Evidence of loss of heterozygosity (LOH) among TSC genes in lesions of different organs in patients with LAM is consistent with the tumour suppressor gene model. The TSC mutations that occur in LAM result in inappropriate and constitutive signalling through the mTOR pathway, which controls protein translation and is activated in many forms of human cancer [14]. Identical somatic TSC mutations have been found in the angiomyolipomas and lungs of the same patient, suggesting that LAM cells might be spread from a common source [5]. In addition, recurrence of LAM in lung transplant recipients and the presence of LAM cells in the blood and other body fluids are consistent with the metastatic behaviour of LAM cells [15-18]. More recently, CD44v6, a glycoprotein that binds hyaluronic acid and is associated with metastatic cancers, has been shown to be expressed on the LAM cell surface [19]. The CD44v6 protein might enable LAM cells to adhere to the extracellular matrix, thus facilitating metastasis.

Although LAM cells exhibit low-grade proliferation and no evidence of cellular atypia, the progressive infiltration of lung parenchyma, tissue destruction, angiogenesis, lymphangiogenesis, and protease-driven matrix degradation are additional features that LAM cells have in common with neoplastic cells [20-23].

\section{Biomarkers}

Vascular endothelial growth factor-D (VEGF-D) is a lymphangiogenic growth factor that is involved in the formation of lymphatic vessels and the spread of tumour cells to lymph nodes. A decade ago, levels of VEGF-D in the serum of patients with sporadic LAM were found to be higher than those detected in 
healthy controls [24]. Subsequently, serum VEGF-D levels in LAM patients were also found to be higher than those in healthy volunteers and in patients with other cystic or chylous lung diseases, including PLCH, emphysema and lymphangiomatosis; all of which suggested that such a parameter could be of value as a diagnostic biomarker [25]. Furthermore, VEGF-D levels were higher in women with TSC and LAM than in women with TSC showing no evidence of cystic changes on CT scans [25].

A subsequent study on a larger population of LAM patients confirmed that serum VEGF-D levels were higher in patients with LAM than in healthy subjects [26]. However, when patient samples were grouped, based on the extent of lymphatic extrapulmonary involvement, the significant difference was maintained only for LAM patients with lymphatic involvement, and higher VEGF-D levels were associated with a higher severity score on CT scan analysis and lower decreased lung diffusion capacity (DLCO); suggesting that serum VEGF-D levels might be a measure of lymphatic involvement in patients with LAM [26].

A prospective study of 48 patients with cystic lung disease of unknown aetiology confirmed the validity of serum VEGF-D concentration as a diagnostic test. According to the authors' findings, serum VEGF-D levels higher than $800 \mathrm{pg} \cdot \mathrm{mL}^{-1}$ could identify LAM with a sensitivity and specificity of 73 and $100 \%$, respectively [27]. A subsequent study of 75 patients with cystic lung disease reported that serum VEGF-D levels could identify LAM with a sensitivity and specificity of $87 \%$ and $90 \%$, respectively, using $468 \mathrm{pg} \cdot \mathrm{mL}^{-1}$ as the diagnostic threshold [28].

Based on these results, the recent American Thoracic Society/Japanese Respiratory Society (ATS/JRS) guidelines on the diagnosis and management of LAM recommended VEGF-D testing for non-invasive diagnostic confirmation of LAM in cases with compatible high-resolution computed tomography (HRCT), when other confirmatory features previously reported by the European Respiratory Society (ERS) guidelines (i.e. TSC, angiomyolipomas, chylous pleural effusions or ascites, and cystic lymphangioleiomyomas) are lacking $[29,30]$. The suggested diagnostic threshold is $800 \mathrm{pg} \cdot \mathrm{mL}^{-1}$ (table 1). The low false positive rate of the test indicates that serum VEGF-D concentrations higher than $800 \mathrm{pg} \cdot \mathrm{mL}^{-1}$ can preclude the need for a lung biopsy in patients with typical HRCT changes. However, serum VEGF-D testing has a high false-negative rate, meaning that a negative result should not be used to rule out or exclude LAM disease. Lung biopsy should still be considered in cases when confirmatory features are lacking. Furthermore, although the $800 \mathrm{pg} \cdot \mathrm{mL}^{-1}$ threshold has subsequently been validated in different cohorts, problems concerning possible inter-laboratory variability should still be considered [31].

Serum VEGF-D might also be useful as a marker of disease severity and response to therapy. The data analysis results of a study on the safety and efficacy of sirolimus in LAM: the Multicenter International Lymphangioleiomyomatosis Efficacy of Sirolimus (MILES) trial, which showed that median serum VEGF-D levels were reduced in the sirolimus group, but remained stable in the placebo group over the treatment period [32]. Interestingly, higher VEGF-D levels at baseline were associated with enhanced improvement in lung function in the sirolimus group and faster lung function decline in the placebo group.

In a retrospective study, serum VEGF-D levels greater than $800 \mathrm{pg} \cdot \mathrm{mL}^{-1}$ were associated with a faster rate of decline in forced vital capacity (FVC) and a faster rate of increase in total lung capacity and residual volume (RV), compared to patients with serum VEGF-D levels less than $800 \mathrm{pg} \cdot \mathrm{mL}^{-1}$ [33].

Matrix metalloproteinases (MMPs) are proteases with a central role in the turnover and degradation of the extracellular matrix. In the lung, they are involved in tissue remodelling and lymphangiogenesis [34].

TABLE 1 Criteria for a definite diagnosis of lymphangioleiomyomatosis according to guidelines

ERS guidelines 2010

ATS/JRS guidelines 2016

$\begin{array}{cc}\text { Characteristic HRCT scans }{ }^{\#} \text { and one of the following: } \\ \text { Tuberous sclerosis complex } & \text { Tuberous sclerosis complex } \\ \text { Chylous effusions } & \text { Chylous effusions } \\ \text { Angiomyolipomas } & \text { Angiomyolipomas } \\ \text { Lymphatic involvement } & \text { Lymphatic involvement } \\ & \text { Serum VEGF-D } \geqslant 800 \mathrm{pg} \cdot \mathrm{mL}^{-1}\end{array}$

\#: numerous (more than 10) thin-walled lung cysts distributed diffusely throughout the lungs without sparing of lung bases, without any other significant pulmonary involvement lexcept for multifocal micronodular pneumocyte hyperplasia in tuberous sclerosis complex). ERS: European Respiratory Society; ATS/JRS: American Thoracic Society/Japanese Respiratory Society; HRCT: high-resolution computed tomography; VEGF-D: vascular endothelial growth factor-D. 
MMPs have been implicated in the pathogenesis of LAM: MMPs are present in LAM lesions; MMP activators have been detected in LAM nodules; and levels of the MMP-3 inhibitor in LAM lesions are lower than those found in normal lung parenchyma [35-37]. Moreover, serum levels of MMP-9 are higher in patients with LAM than in normal subjects [38]. More recently, overexpression of MMPs has been shown in cells lacking TSC1/TSC2 [39]. It can be hypothesised that degradation of the extracellular matrix by MMPs can facilitate cell migration and contribute to the formation of lung cysts [35].

Monitoring of serum and urinary MMPs could be a useful, though not specific, assessment of disease severity and response to treatment in patients with LAM $[40,41]$. In one patient with severe LAM, urinary levels of MMP-9 and MMP-2 became undetectable after 3 months of treatment with doxycycline, an inhibitor of MMPs [42]. Furthermore, an open-label, interventional clinical trial on the efficacy and safety of doxycycline showed that serum MMP-9 and MMP-2 levels were significantly reduced after 6 months of treatment [43]. In a randomised, placebo-controlled clinical trial of doxycycline, the urine levels of MMP-9 were significantly lower in the doxycycline-treated patients than in the placebo group over the 2 -year treatment period, whereas no significant difference was found in the serum levels of MMP-2 or MMP-9 between the two groups over the same period [44].

The TSC LOH is involved in the pathogenesis of LAM; LAM cells, identified by TSC2 LOH, have been isolated from the blood and other body fluids of LAM patients $[17,18]$. Furthermore, detection of the $\mathrm{LOH}$ is reduced after treatment with sirolimus, suggesting that the search for circulating LAM cells in the blood or other fluids might identify patients at risk of disease progression or spread and/or the response to potential therapy $[45,46]$. Recently, different $\mathrm{LOH}$ patterns in different subpopulations of LAM cells, in various body fluids, have been identified over time in the same patient [47]. These findings suggest that a single patient might have different clones of LAM cells.

The TSC2 LOH has been recently reported in the blood of patients with other pulmonary diseases, including sarcoidosis and PLCH, but not in the same populations of cells in which LAM cells are typically found [48]. However, whether TSC LOH in body fluids could have a clinical role in the management of LAM has yet to be determined.

\section{Lung function impairment}

The most common respiratory symptom of LAM is dyspnoea (over $70 \%$ of patients), although pulmonary function tests (PFTs) can be normal in up to $30 \%$ of patients $[49,50]$. Airflow obstruction and decreased lung diffusion capacity (DLCO) are the most frequent functional abnormalities [49-52]. Both airflow limitation and DLCO correlate with disease severity, assessed by CT scan, LAM histology score and exercise capacity $[13,53-56] .25-30 \%$ of LAM patients show reversible airflow obstruction $[51,53]$. The decline in forced expiratory volume in $1 \mathrm{~s}$ (FEV1) in untreated patients is variable and mostly unpredictable; the mean annual decline in $\mathrm{FEV}_{1}$ reportedly ranges from 60 to $134 \mathrm{~mL}$ per year among different retrospective studies and clinical trials [12, 44, 57, 58].

LAM patients frequently experience reduced exercise tolerance. Reduced performance during cardiopulmonary exercise testing (CPET) is common, with decreased maximal workload and oxygen consumption $\left(V^{\prime} \mathrm{O}_{2}\right)$, mainly due to ventilatory and gas exchange abnormalities [51, 59]. Dynamic hyperinflation $(\mathrm{DH})$ can frequently develop during incremental CPET, and could be associated with the severity of disease, higher desaturation and increased dyspnoea [60]. In another study of 38 patients, inhalation of salbutamol caused a slight improvement in $\mathrm{FEV}_{1}$, but did not produce a significant reduction in $\mathrm{DH}$ or dyspnoea during submaximal exercise in comparison to the placebo [61]. Interestingly, a recent study on physical activity in daily life showed that each of the three parameters of physical activity (steps per day, physical activity level and minutes of moderate activity) were reduced in LAM patients, compared to healthy controls. After adjusting for age and long-term oxygen therapy, physical activity level and minutes of moderate activity were significantly lower in LAM patients, compared to chronic obstructive pulmonary disease (COPD) patients. These findings suggest a disease-specific impact on daily physical activity beyond airflow limitations in LAM patients [62].

\section{Therapy}

Both sirolimus and everolimus, two mTORC1 inhibitors, target the mTOR activated signalling pathway, thus inhibiting growth and proliferation of LAM cells [63].

The efficacy of sirolimus in reducing angiomyolipoma volume and increasing functional parameters in patients with LAM was first demonstrated a decade ago in a pilot study, the Cincinnati Angiomyolipoma Sirolimus Trial (CAST) [64].

The MILES trial, a randomised placebo-controlled trial on the safety and efficacy of sirolimus in patients with moderate functional impairment, showed the stabilisation of FEV1 during the 12-month treatment 
period, with frequent, but mostly mild to moderate adverse events (i.e. mucositis, gastrointestinal events, hypercholesterolaemia, acneiform rash and swelling in the lower extremities) [58]. Improvement in FVC, quality of life and serum VEGF-D levels were also observed. Discontinuation of therapy caused a more rapid decline in lung function, similar to that in the placebo group, suggesting the need for continuous treatment. Sirolimus also improved chylous manifestations of the disease, such as the volume of chylous effusions and lymphangioleiomyomas [65].

More recently, the effects of sustained treatment with sirolimus have been reported in an observational study of a cohort of 38 patients with LAM, including patients with lymphatic complications. Treatment with sirolimus for a period of about 3.5 years stabilised lung function, by slowing the decline in FEV1 and DLCO, and changes in lung volume occupied by cysts, with an acceptable spectrum of toxicities. The effect was maintained in a subgroup of 12 patients followed for about 5 years [66].

Another current concern about therapy with mTOR inhibitors is whether low doses of the drug could be used to maintain therapeutic effects and reduce toxicity. A retrospective study in a small cohort of patients before and after therapy suggested that sirolimus might be effective in maintaining lung function and controlling chylous effusions even at a serum trough level less than $5 \mathrm{ng} \cdot \mathrm{mL}^{-1}$ [67]. However, the incidence of adverse events was similar to that reported in previous studies, except for hypercholesterolaemia. Prospective studies comparing conventional and low-dose mTOR inhibitor regimens are necessary.

Two randomised controlled trials (EXIST-1 and EXIST-2) showed that everolimus, a second-generation mTOR1 inhibitor, was effective in reducing the size of giant cell astrocytomas in patients with TSC and decreasing the size of renal angiomyolipomas in patients with TSC or LAM $[68,69]$. An exploratory, open-label, non-randomised, within-subject dose escalation trial of everolimus in 24 patients with sporadic or TSC-LAM was subsequently conducted [70]. That study showed that the safety profile of everolimus was similar to that of sirolimus in the MILES trial. Four serious drug-related adverse events were observed, including pneumocystis, heart failure, and pneumonia, which were not observed in the MILES study. The VEGF-D levels decreased throughout the duration of therapy. Treatment with everolimus resulted in stabilisation of the FVC and improvement in FEV1, relative to baseline. When comparing efficacy results after 26 weeks of treatment with the data obtained in the placebo-controlled group of the MILES trial, the improvement in FEV1 observed was slightly greater than the absolute difference seen between sirolimus and placebo in the MILES study, and the improvement in FVC was smaller than that observed in the MILES study [70].

Recent ATS/JRS guidelines recommend treatment with sirolimus for patients with abnormal lung function, defined as an FEV1 less than $70 \%$ predicted, or patients with declining lung function. The panel members for those guidelines also recommend sirolimus for patients with symptomatic chylous fluid effusions before invasive procedures are considered [29].

To date, hormonal treatments including progesterone, GnRH antagonists, oophorectomy, and anti-oestrogen therapy with tamoxifen are not recommended, because results of available studies are controversial or inconclusive, and no controlled clinical trial has been conducted [71-76]. A randomised, controlled trial comparing the aromatase inhibitor letrozole with a placebo in postmenopausal women with LAM has been concluded, but the official results are not yet available (NCT01353209).

Doxycycline is a tetracycline antibiotic that inhibits the production and activity of several MMPs; its potential role in the treatment of LAM was suggested in a report of a patient with severe pulmonary impairment, in whom the treatment with this drug improved lung function [42]. Two subsequent open-label, uncontrolled trials showed that the drug led to a reduction in serum and urinary MMPs; moreover, it was well tolerated in most patients, and was effective in improving FEV1 in a subgroup of patients with higher baseline FEV1 [43, 77]. However, the follow-up analysis showed that rates of lung function decline could differ between responders and non-responders, because of the variability in disease severity at baseline [78]. More recently, a double-blind, placebo-controlled clinical trial of doxycycline failed to show differences in the mean yearly decline in FEV1 between the placebo and treatment groups. However, these results should be interpreted with caution, because of the limited number of patients who completed the 24-month treatmentperiod, due to the high dropout rate [44].

Recurrence of disease-related symptoms and complications after cessation of therapy with mTOR inhibitors might occur; moreover, patients might not respond to or even be intolerant of the treatment. All of these findings suggest that mTOR inhibitors are not curative, and have therefore led to a focus on novel therapeutic strategies. Recent advances in understanding the pathogenesis of LAM suggest new potential targets.

Autophagy is a critical component of TSC tumorigenesis that is increased by mTOR inhibition, which probably enhances LAM cell survival and reduces the effects of mTOR inhibitors [79]. The inhibition of 
autophagy in combination with mTOR inhibition has been shown to be more effective than either treatment alone, in inhibiting survival of TSC2-null cells, the growth of TSC2-null xenograft tumours and development of spontaneous renal tumours in Tsc2+/- mice [79]. The results of a phase I clinical trial on the safety and tolerability of sirolimus in combination with hydroxychloroquine in patients with LAM have been recently published [80]. 13 patients in cohorts of three patients each were treated with sirolimus and increasing hydroxychloroquine doses (200 and $400 \mathrm{mg}$ daily), and an extension phase at the $400 \mathrm{mg}$ dose. The treatment period was 24 months, followed by an observation phase off any of the drugs under study for an additional 24 weeks. Mucositis, headache, and diarrhoea were the most common adverse events, whereas no serious drug-related adverse events were observed. Analysis of secondary endpoints showed an improvement in FEV1 and FVC at 24 weeks, both of which remained stable when the higher dose of hydroxychloroquine was analysed separately. Larger trials are needed to explore the effects on lung function.

A deficiency of tuberin due to TSC2 mutations results in increased RhoA GTPase activity and cell survival, an effect that is mediated through mTOR complex 2 signalling. Because of their inhibitory effects on RhoA GTPase, statins have been considered as a possible therapy in LAM [81]. A retrospective study of patients who were treated with a combination of sirolimus and simvastatin, or with either sirolimus alone or simvastatin alone because of hypercholesterolaemia, showed that the combined therapy had no beneficial effect and did not increase the incidence of adverse events, beyond those expected from the use of each drug alone [82]. A phase 1-2 clinical trial on combination therapy with simvastatin and mTOR inhibitors (everolimus and sirolimus) is ongoing (NCT02061397).

The Src kinases, the degradation of which is promoted by autophagy, are key regulators of cellular proliferation, motility and invasiveness. Thus, decreased autophagy due to mTOR activation in LAM cells might play a role in the accumulation of active Src in these cells. An increase in active Src has been found in the lung tissues of patients with LAM and in cultured TSC2-/- cells [83]. Furthermore, increased Src kinase activation facilitates migration, invasion and inhibition of E-cadherin expression in TSC2-/- cells by upregulating its transcriptional repressor. A phase 1-2 clinical trial of safety and efficacy of the inhibitor of Src kinases, saracatinib (SLAM-2), in patients with LAM is underway (NCT02737202).

The platelet-derived growth factor receptor $\beta$ (PDGFR $\beta)$ is present and active in human and murine TSC lesions [84]. The safety and efficacy of nintedanib, a small potent inhibitor of the tyrosine kinase FGR receptor, VEGF receptor, and the platelet-derived growth factor (PDGF) receptor is currently being investigated in a pilot study of patients with LAM (NCT03062943). The inhibition of tumour angiogenesis and lymphangiogenesis promoted by PDGF, FGR and VEGF could play a role in preventing the dissemination of LAM cells and disease progression in LAM.

\section{Pulmonary Langerhans cell histiocytosis What is PLCH?}

Langerhans cell histiocytosis (LCH) is a rare histiocytic disorder of unknown origin that could affect patients of any age, but is most common in children from 1 to 3 years old.

Different clinical forms of $\mathrm{LCH}$ have been categorised into systemic and localised forms. Localised $\mathrm{LCH}$ often affects the bone, skin and lung, and is characterised by a good prognosis with occasional spontaneous resolution. Systemic LCH affects more than one organ or tissue (e.g. bone, skin, hypothalamic-pituitary system, lymph nodes, lungs and more rarely, the central nervous system). The involvement of the so-called "risk organs", such as the liver, spleen and haematopoietic system, is a well-established unfavourable prognosticator [85]. The lung could be involved as a single organ, typically in young smoker adults with equal gender distribution (PLCH), whereas it is less frequently affected in the systemic form of LCH [86]. The pathogenesis of PLCH is still unclear. Various molecular mechanisms underlying disease pathogenesis and progression have been found.

The characteristics of PLCH include an accumulation of a large number of CD1a+ cells (Langerhans cells (LC)) in loosely formed bronchiolocentric granulomas. This results in airspace invasion, cavitation and consequent destruction of lung parenchyma. Myeloid haematopoietic precursors are recruited from circulating peripheral blood that further differentiate in the LC of involved tissues. Local growth factors, such as granulocyte macrophage colony stimulating factor (GM-CSF) and chemokines (CCL20 and CCL2), have been found around PLCH lesions, and can enhance this differentiation [87, 88]. The presence of local neoangiogenesis in association with the action of cell adhesion molecules could contribute to the accumulation of LC, T lymphocytes and inflammatory cells [89]. A peculiar characteristic of PLCH granulomas is their ability to destroy and remodel the surrounding lung parenchyma [90]. The mechanism is still unclear, but CD1a+ cells found in the granulomas show a different phenotype, compared to the 
same cells grown under physiological conditions in vitro. In fact, different types of markers of membrane maturation have been detected in LC granulomas. These markers are similar to those usually found on the surface of dendritic cells after exposure to various pathogens [91]. However, the CD1a+ cell-mediated cytotoxic action of $\mathrm{T}$ lymphocytes seems to be impaired, and for this reason, CD1a+ cells are unlikely to be the only cause of tissue destruction. Several metalloproteinases that have been found in $\mathrm{LCH}$ granulomas might also be involved in parenchymal damage [92]. Moreover, interleukin-17 might be involved in tissue remodelling [93]. In addition, activation of Notch1 signalling pathways seems to be responsible for the peculiar phenotype of LCH cells [94].

Whether PLCH is a reactive or clonal/neoplastic disease is still an important question that pertains to the pathogenesis of PLCH. The hypothesis of a reactive response to an unknown agent is supported by the large number of inflammatory/immune cells found in PLCH granulomas, and by the absence of pathological features like mitotic figures, or frequent spontaneous resolution after smoking cessation [95].

Furthermore, one study that analysed CD1a+ cells from lung biopsies of PLCH patients revealed the polyclonal nature of these cells [96]. Another study conducted on LC derived from extrapulmonary lesions of focal or systemic forms of LCH reported a clonal nature of these cells [97]. Therefore, the issue remains a controversial one.

The recent findings of a proto-oncogene mutation $\left(\mathrm{BRAF}^{\mathrm{V} 600 \mathrm{E}}\right)$ in $38 \%$ to $69 \%$ of the $\mathrm{LC}$ in systemic $\mathrm{LCH}$ granulomas [98-101], in $28 \%$ of patients with PLCH [86], and in 54\% to $82 \%$ of patients with ErdheimChester Disease (ECD) $[102,103]$, supports the neoplastic theory. In fact, the BRAF ${ }^{\mathrm{V} 600 \mathrm{E}}$ mutation has been found in different tumours, such as malignant melanomas and in almost all cases of hairy cell leukaemia [104].

The $\mathrm{BRAF}^{\mathrm{V} 600 \mathrm{E}}$ mutation determines the constitutive activation of the mitogen activated protein kinase (MAPK) pathway, thus deregulating the control system of cell differentiation and survival. Interestingly, MAPK pathway-independent activation in LCH granulomas has been found, even in the absence of $\mathrm{BRAF}^{\mathrm{V} 600 \mathrm{E}}$ mutations, suggesting a key role of MAPK in LCH pathogenesis $[105,106]$.

The simultaneous presence of $\mathrm{NRAS}^{\mathrm{Q} 61} \mathrm{~K}^{/ \mathrm{R}}$ and $\mathrm{BRAF}^{\mathrm{V} 600 \mathrm{E}}$ mutations carried by different cell clones has been demonstrated in several PLCH lesions [107]. Moreover, NRAS ${ }^{\mathrm{Q} 61}$ has been found in lung lesions, but not in systemic LCH lesions. In one patient, the NRAS mutation occurred in pulmonary lesions, but not in skin lesions.

The role of genetic mutations in $\mathrm{LCH}$ and $\mathrm{PLCH}$ is still not fully understood. Patients with the BRAF ${ }^{\mathrm{V} 600 \mathrm{E}}$ mutation in LC were generally younger compared to non-carrier $\mathrm{BRAF}^{\mathrm{V} 600 \mathrm{E}}$ patients; however, no link was observed with the phenotype. Furthermore, the mutation increased the risk of recurrence of the disease, without any changes in survival [108]. In addition, children with the BRAF ${ }^{\mathrm{V} 600 \mathrm{E}}$ mutation show increased resistance to first-line treatment [109]. Further studies are needed to determine whether the involvement of BRAF and MAPK pathways could be useful for the stratification of patients affected by PLCH and identification of specific outcomes.

A large amount of evidence confirms the key role of smoking in the pathogenesis of PLCH. The rarity of the disease compared to smoking rates in the general population suggest a predisposition in patients affected by the disease. The pathogenic mechanism by which smoking could induce the disease remains unclear. Smoking induces changes in the epithelium of distal bronchioles and an accumulation of CD1a+ cells in healthy smokers, different lung diseases and in murine models [107]. Furthermore, it stimulates the production of local cytokines involved in the proliferation, differentiation and activation of dendritic cells in PLCH lesions [110-112].

Osteopontin, a glycoprotein, the secretion of which is increased by nicotine, was increased in the bronchoalveolar lavage (BAL) fluid of smoking patients with $\mathrm{PLCH}$, compared to that of healthy smokers. Osteopontin has a chemoactive effect on monocytes/macrophages and dendritic cells; moreover, its overexpression in murine models creates PLCH-like lesions [113].

\section{Biomarkers}

PLCH is a disease with a very typical radiological pattern, which may be diagnostic if clinically consistent. However, some useful biomarkers could improve the diagnostic process, particularly in the presence of atypical manifestations. BAL can be useful in the diagnosis of PLCH [114]. Differential cell counts in PLCH patients might reveal an increase in eosinophils and neutrophils compared to healthy smokers, with a normal percentage of lymphocytes [115]. Elevated numbers of CD1a+ BAL cells have been found in PLCH and, interestingly, the number of these cells is not influenced by smoking habits; thus, any number of CD1a+ BAL cells greater than $5 \%$ of the total number of cells is considered a biological marker of PLCH [116]. 
The CD207 (an antibody against langerin) is another useful LC marker. The quantity of this protein in the BAL fluid of PLCH patients is significantly increased compared to that of patients with sarcoidosis and idiopathic pulmonary fibrosis [117].

Transbronchial lung biopsies have shown poor sensitivity for the diagnosis of PLCH, because of the patchy nature of the disease with a focal distribution, and the small amount of tissue that can be obtained with this procedure [118]. Instead, with the use of cryobiopsy, larger samples can be obtained, thereby increasing the diagnostic yield [119]. Unfortunately, these procedures can all be complicated by pneumothorax; thus, surgical lung biopsy seems to be a safer procedure to obtain tissue samples. Techniques of immunohistochemistry using monoclonal antibodies against CD1a and langerin (CD207) facilitate the detection of LC in lung biopsies. In contrast, detection of cytoplasmic protein S100 is not a specific assay.

The BRAF ${ }^{\mathrm{V} 600 \mathrm{E}}$ mutation, as previously mentioned, is frequently associated with $\mathrm{LCH}, \mathrm{ECD}$ and in some cases, PLCH. Immunohistochemical detection of its expression is an effective method, following bioptic tissue confirmation, for screening patients who could benefit from specific treatment. However, it could be very difficult to detect mutations in tissue biopsies from histiocytosic patients. It is for this reason that a droplet-digital PCR assay for quantitative detection of $\mathrm{BRAF}^{\mathrm{V} 600 \mathrm{E}}$ mutation in plasma and urine cell-free DNA has been recently performed in patients with ECD or LCH. The procedure provided a reliable method to detect the mutation and monitor the response to specific treatments with RAF inhibitors [120, 121].

Fluorodeoxyglucose-positron emission tomography (FDG-PET) scan can play a role as a radiological biomarker. Fluorodeoxyglucose is absorbed and metabolised by LC, thereby enhancing the identification of histiocytic lesions in different organs. Although this technique is neither sensitive nor specific for pulmonary lesions, it is particularly useful in detecting multisystem involvement of LCH and assessing skeletal involvement [122].

\section{Lung function impairment}

Patients affected by PLCH frequently show a reduction in DLCO [86]. An obstructive respiratory pattern on PFTs has been observed in up to $50 \%$ of patients, whereas a restrictive pattern has been described in a small number of patients [123]. Severity of airflow limitation is significantly related to the parenchymal extension of the disease [124].

Daily activities are largely limited in PLCH patients. Decreased maximum oxygen consumption $\left(V^{\prime} \mathrm{O}_{2}\right.$ peak) and reduced 6-min walking distance have both been demonstrated. A correlation between $V^{\prime} \mathrm{O}_{2}$ peak and resting dead space/tidal volume ratio $(V \mathrm{D} / V \mathrm{~T}), \mathrm{RV}$ and resting alveolar-to-arterial oxygen tension difference, and DLCO have also been observed [125]. Recently, Rolland-DeBord et al. [126] collected data on dyspnoea, PFT and CPET in 62 patients. 44 subjects $(71 \%)$ showed exercise limitation $\left(V^{\prime} \mathrm{O}_{2}\right.$ peak $<84 \%)$. No difference was found in dyspnoea score between patients with impaired and normal aerobic capacity. Despite possible biases related to the retrospective design of the study, multidimensional analysis

TABLE 2 Distinctive features of lymphangioleiomyomatosis (LAM) and pulmonary Langerhans cell histiocytosis (PLCH)

\begin{tabular}{|c|c|c|}
\hline & LAM & PLCH \\
\hline Related to smoking & Not evident & Strong \\
\hline Gender predilection & Yes (female) & No \\
\hline Genetic mutations & $\begin{array}{c}\text { TSC1 or more frequently, } \\
\text { TSC2 }\end{array}$ & BRAF $^{\mathrm{V} 600 \mathrm{E}}, \mathrm{NRAS}, \mathrm{MAP} 2 \mathrm{~K} 1$ \\
\hline HRCT pattern & Cystic & $\begin{array}{c}\text { Nodular-cystic } \\
\text { Cystic } \\
\text { Nodular }\end{array}$ \\
\hline Multisystem involvement & Frequent & Possible \\
\hline Treatment & Sirolimus ${ }^{\#}$ & $\begin{array}{c}\text { Smoking cessation } \\
\text { Steroids } \\
\text { Vinblastine } \\
\text { Possible role of cladribrine and BRAF } \\
\text { inhibitors }\end{array}$ \\
\hline
\end{tabular}

\footnotetext{
\#: approved by the US Food and Drug Administration in 2015, recognised as orphan drug by the European Medicines Agency in 2016. HRCT: high-resolution computed tomography.
} 
showed that the reduction of aerobic exercise capacity in patients with PLCH has a multifactorial origin, which includes gas exchange, air trapping, ventilatory abnormalities and hyperpnoea [126].

\section{Therapy}

The first therapeutic approach recommended for patients affected by PLCH is smoking cessation [127, 128]. Smoking cessation for at least 6 months is associated with reduced longitudinal decline in lung function [125]. The efficacy of this approach on extrapulmonary manifestations is not yet well defined. Although smoking cessation is the only treatment required for most patients, oral corticosteroids are also frequently prescribed for patients with progressive functional deterioration, despite smoking cessation. Unfortunately, strong evidence of the efficacy of this treatment in this population is still lacking, because all studies have been retrospective and have not taken the effects of smoking cessation into consideration [129].

Some case series have reported the results obtained with the use of chemotherapies such as vinblastine, methotrexate, cyclophosphamide and etoposide in patients with progressive disease that is non-responsive to steroids, or with multiorgan involvement [130-132]; no clear improvement in the patients' condition was observed. For this reason, these treatments should be reserved as rescue therapies in a limited number of non-responding patients. Cladribine (2-chlorodeoxyadenosine) is a drug with cytotoxic effects on lymphocytes and monocytes. It has been shown to be effective in some patients with progressive PLCH, and in a small number of adult patients with a multisystem or aggressive multifocal form of LCH, when used alone or in combination with corticosteroids [133]. Furthermore, in a retrospective study conducted on a small number of patients, cladribine was found to improve respiratory function and reduce the size of cysts, even in patients with advanced disease [134, 135]. A clinical phase II open-label trial on the efficacy of cladribine in PLCH patients with functional pulmonary deterioration is ongoing (NCT01473797).

Findings of the presence of the BRAF ${ }^{\mathrm{V} 600 \mathrm{E}}$ mutation in $\mathrm{LCH}, \mathrm{ECD}$ and $\mathrm{PLCH}$ have raised the possibility of targeted therapies in selected patients. Vemurafenib, an inhibitor of mutant BRAF that is used in the treatment of $\mathrm{BRAF}^{\mathrm{V} 600 \mathrm{E}}$-associated hairy cell leukaemia [136], has been successfully used in three patients with multisystemic and refractory ECD, leading to a rapid clinical and biologic improvement, just 1 month after treatment. Furthermore, vemurafenib administered to eight patients with $\mathrm{BRAF}^{\mathrm{V} 600 \mathrm{E}}$ mutation-multisystemic ECD, which was refractory to first-line treatment, resulted in an improvement of general symptoms and a persistent response, with a median follow-up time of 10.5 months (range 6-16 months). Adverse effects on the skin were frequent and severe [137]. Recently, $18 \mathrm{BRAF}^{\mathrm{V} 600 \mathrm{E}}$ mutation-positive ECD/LCH patients were treated with a BRAF inhibitor, resulting in stabilisation of the disease in the majority of cases. Interestingly, no disease progression has been reported during this form of treatment [138].

\section{Conclusions}

The conditions LAM and PLCH are the most common pulmonary cystic diseases. They both differ in their pathogenic mechanisms, neither of which are yet fully understood. Currently, both diseases seem to act as neoplastic disorders with extrapulmonary involvement. In particular, the extrapulmonary involvement might occur more frequently in LAM patients (table 2). Findings on the pathogen-associated molecular patterns of the diseases raise possibilities of the use of new therapeutic strategies. However, the results of ongoing studies, which hopefully will only be the start of further clinical investigations, will aid in establishing better comprehension of the possible role of novel therapeutic options. Targeting multiple signalling pathways might be a strategy for managing LAM, whereas cladribine and BRAF inhibitors are presently the most promising treatments for aggressive PLCH.

\section{References}

1 Gupta N, Vassallo R, Wikenheiser-Brokamp KA, et al. Diffuse cystic lung disease. Part I. Am J Respir Crit Care Med 2015; 191: 1354-1366.

2 Harari S, Torre O, Moss J. Lymphangioleiomyomatosis: what do we know and what are we looking for? Eur Respir Rev 2011; 20: 34-44.

3 Franz DN, Brody A, Meyer C, et al. Mutational and radiographic analysis of pulmonary disease consistent with lymphangioleiomyomatosis and micronodular pneumocyte hyperplasia in women with tuberous sclerosis. Am J Respir Crit Care Med 2001; 164: 661-666.

$4 \quad$ Sparagana SP, Roach ES. Tuberous sclerosis complex. Curr Opin Neurol 2000; 13: 115-119.

5 Carsillo T, Astrinidis A, Henske EP. Mutations in the tuberous sclerosis complex gene TSC2 are a cause of sporadic pulmonary lymphangioleiomyomatosis. Proc Natl Acad Sci USA 2000; 97: 6085-6090.

$6 \mathrm{Yu} \mathrm{J}$, Astrinidis A, Henske EP. Chromosome 16 loss of heterozygosity in tuberous sclerosis and sporadic lymphangiomyomatosis. Am J Respir Crit Care Med 2001; 164: 1537-1540.

7 Sato T, Seyama K, Fujii H, et al. Mutation analysis of the TSC1 and TSC2 genes in Japanese patients with pulmonary lymphangioleiomyomatosis. J Hum Genet 2002; 47: 20-28.

8 Schmelzle T, Hall MN. TOR, a central controller of cell growth. Cell 2000; 103: 253-262.

9 Inoki $\mathrm{K}, \mathrm{Li} \mathrm{Y}, \mathrm{Xu}$ T, et al. Rheb GTPase is a direct target of TSC2 GAP activity and regulates mTOR signaling. Genes Dev 2003; 17: 1829-1834. 
10 Saucedo LJ, Gao X, Chiarelli DA, et al. Rheb promotes cell growth as a component of the insulin/TOR signalling network. Nat Cell Biol 2003; 5: 566-571.

11 Matsumoto Y, Horiba K, Usuki J, et al. Markers of cell proliferation and expression of melanosomal antigen in lymphangioleiomyomatosis. Am J Respir Cell Mol Biol 1999; 21: 327-336.

12 Zhe X, Schuger L. Combined smooth muscle and melanocytic differentiation in lymphangioleiomyomatosis. J Histochem Cytochem 2004; 52: 1537-1542.

13 Martignoni G, Pea M, Reghellin D, et al. Molecular pathology of lymphangioleiomyomatosis and other perivascular epithelioid cell tumors. Arch Pathol Lab Med 2010; 134: 33-40.

14 Inoki K, Corradetti MN, Guan KL. Dysregulation of the TSC-mTOR pathway in human disease. Nat Genet 2005; 37: 19-24.

15 Karbowniczek M, Astrinidis A, Balsara BR, et al. Recurrent lymphangiomyomatosis after transplantation: genetic analyses reveal a metastatic mechanism. Am J Respir Crit Care Med 2003; 167: 976-982.

16 Karbowniczek M, Yu J, Henske EP. Renal angiomyolipomas from patients with sporadic lymphangiomyomatosis contain both neoplastic and non-neoplastic vascular structures. Am J Pathol 2003; 162: 491-500.

17 Crooks DM, Pacheco-Rodriguez G, DeCastro RM, et al. Molecular and genetic analysis of disseminated neoplastic cells in lymphangioleiomyomatosis. Proc Natl Acad Sci USA 2004; 101: 17462-17467.

18 Cai X, Pacheco-Rodriguez G, Fan QY, et al. Phenotypic characterization of disseminated cells with TSC2 loss of heterozygosity in patients with lymphangioleiomyomatosis. Am J Respir Crit Care Med 2010; 182: 1410-1418.

19 Pacheco-Rodriguez G, Steagall WK, Crooks DM, et al. TSC2 loss in lymphangioleiomyomatosis cells correlated with expression of CD44v6, a molecular determinant of metastasis. Cancer Res 2007; 67: 10573-10581.

20 Boehlke C, Kotsis F, Patel V, et al. Primary cilia regulate mTORC1 activity and cell size through Lkb1. Nat Cell Biol 2010; 12: 1115-1122.

21 Goncharova EA, Goncharov DA, Lim PN, et al. Modulation of cell migration and invasiveness by tumor suppressor TSC2 in lymphangioleiomyomatosis. Am J Respir Cell Mol Biol 2006; 34: 473-480.

22 Kumasaka T, Seyama K, Mitani K, et al. Lymphangiogenesis-mediated shedding of LAM cell clusters as a mechanism for dissemination in lymphangioleiomyomatosis. Am J Surg Pathol 2005; 29: 1356-1366.

23 Chilosi M, Pea M, Martignoni G, et al. Cathepsin-K expression in pulmonary lymphangioleiomyomatosis. Mod Pathol 2009; 22: 161-166.

24 Seyama K, Kumasaka T, Souma S, et al. Vascular endothelial growth factor-D is increased in serum of patients with lymphangioleiomyomatosis. Lymphat Res Biol 2006; 4: 143-152.

25 Young LR, Inoue Y, McCormack FX. Diagnostic potential of serum VEGF-D for lymphangioleiomyomatosis. N Engl J Med 2008; 358: 199-200.

26 Glasgow CG, Avila NA, Lin JP, et al. Serum vascular endothelial growth factor-D levels in patients with lymphangioleiomyomatosis reflect lymphatic involvement. Chest 2009; 135: 1293-1300.

27 Young LR, Vandyke R, Gulleman PM, et al. Serum vascular endothelial growth factor-D prospectively distinguishes lymphangioleiomyomatosis from other diseases. Chest 2010; 138: 674-681.

28 Radzikowska E, Jaguś P, Skoczylas A, et al. Role of serum vascular endothelial growth factor D in discrimination of patients with polycystic lung diseases. Pol Arch Med Wewn 2013; 123: 533-538.

29 McCormack FX, Gupta N, Finlay GR, et al. Official American Thoracic Society/Japanese Respiratory Society Clinical Practice Guidelines: Lymphangioleiomyomatosis Diagnosis and Management. Am J Respir Crit Care Med 2016; 194: 748-761.

30 Johnson SR, Cordier JF, Lazor R, et al. European Respiratory Society guidelines for the diagnosis and management of lymphangioleiomyomatosis. Eur Respir J 2010; 35: 14-26.

31 Harari S, Cassandro R, Torre O. The ATS/JRS guidelines on lymphangioleiomyomatosis: filling in the gaps. Am J Respir Crit Care Med 2017; 196: 659-660.

32 Young L, Lee HS, Inoue Y, et al. Serum VEGF-D a concentration as a biomarker of lymphangioleiomyomatosis severity and treatment response: a prospective analysis of the Multicenter International Lymphangioleiomyomatosis Efficacy of Sirolimus (MILES) trial. Lancet Respir Med 2013; 1: 445-452.

33 Radzikowska E, Jaguś $\mathrm{P}$, Sobiecka $\mathrm{M}$, et al. Correlation of serum vascular endothelial growth factor-D concentration with clinical presentation and course of lymphangioleiomyomatosis. Respir Med 2015; 109: 1469-1475.

34 Ji RC. Lymphatic endothelial cells, lymphangiogenesis, and extracellular matrix. Lymphat Res Biol 2006; 4: $83-100$.

35 Matsui K, Takeda K, Yu Z-X, et al. Role for activation of matrix metalloproteinases in the pathogenesis of pulmonary lymphangioleiomyomatosis. Arch Pathol Lab Med 2000; 124: 267-275.

36 Zhe X, Yang Y, Jakkaraju S, et al. Tissue inhibitor of metalloproteinase-3 downregulation in lymphangioleiomyomatosis. Am J Respir Cell Mol Biol 2003; 28: 504-511.

37 Krymskaya VP, Shipley JM. Lymphangioleiomyomatosis: a complex tale of serum response factor-mediated tissue inhibitor of metalloproteinase-3 regulation. Am J Respir Cell Mol Biol 2003; 28: 546-550.

38 Lamb RF, Roy C, Diefenbach TJ, et al. The TSC1 tumour suppressor hamartin regulates cell adhesion through ERM proteins and the GTPase Rho. Nat Cell Biol 2000; 2: 281-287.

39 Lee PS, Tsang SW, Moses MA, et al. Rapamycin-insensitive up-regulation of MMP2 and other genes in tuberous sclerosis complex 2-deficient lymphangioleiomyomatosis-like cells. Am J Respir Cell Mol Biol 2010; 42: 227-234.

40 Moses MA, Wiederschain D, Loughlin KR, et al. Increased incidence of matrix metalloproteinases in urine of cancer patients. Cancer Res 1998; 58: 1395-1399.

41 Roy R, Yang J, Moses MA. Matrix metalloproteinases as novel biomarkers and potential therapeutic targets in human cancer. J Clin Oncol 2009; 27: 5287-5297.

42 Moses MA, Harper J, Folkman J. Doxycycline treatment for lymphangioleiomyomatosis with urinary monitoring for MMPs. N Engl J Med 2006; 324: 2621-2622.

43 Pimenta SP, Baldi BG, Kairalla RA, et al. Doxycycline use in patients with lymphangioleiomyomatosis: biomarkers and pulmonary function response. J Bras Pneumol 2013; 39: 5-15.

44 Chang WY, Cane JL, Kumaran M, et al. A 2-year randomised placebo-controlled trial of doxycycline for lymphangioleiomyomatosis. Eur Respir J 2014; 43: 1114-1123. 
Cai X, Pacheco-Rodriguez G, Haughey M, et al. Sirolimus decreases circulating lymphangioleiomyomatosis cells in patients with lymphangioleiomyomatosis. Chest 2014; 145: 108-112.

Harari S, Elia D, Torre O, et al. Sirolimus therapy for patients with lymphangioleiomyomatosis leads to loss of chylous ascites and circulating LAM cells. Chest 2016; 150: e29-e32.

Steagall WK, Zhang L, Cai X, et al. Genetic heterogeneity of circulating cells from patients with lymphangioleiomyomatosis with and without lung transplantation. Am J Respir Crit Care Med 2015; 191: 854-856.

Zhang L, Pacheco-Rodriguez G, Steagall WK, et al. Tuberous sclerosis complex 2 loss of heterozygosity in patients with lung disease and cancer. Am J Respir Crit Care Med 2015; 191: 352-355.

Ryu JH, Moss J, Beck GJ, et al. The NHLBI lymphangioleiomyomatosis registry: characteristics of 230 patients at enrollment. Am J Respir Crit Care Med 2006; 173: 105-111.

Cohen MM, Pollock-BarZiv S, Johnson SR. Emerging clinical picture of lymphangioleiomyomatosis. Thorax 2005; 60: 875-879.

Taveira-DaSilva AM, Stylianou MP, Hedin CJ, et al. Maximal oxygen uptake and severity of disease in lymphangioleiomyomatosis. Am J Respir Crit Care Med 2003; 168: 1427-1431.

Hayashida M, Seyama K, Inoue Y, et al. The epidemiology of lymphangioleiomyomatosis in Japan: a nationwide cross-sectional study of presenting features and prognostic factors. Respirology 2007; 12: 523-530.

Avila NA, Chen CC, Chu SC, et al. Pulmonary lymphangioleiomyomatosis: correlation of ventilation-perfusion scintigraphy, chest radiography, and CT with pulmonary function tests. Radiology 2000; 214: 441-446.

Matsui K, Beasley MB, Nelson WK, et al. Prognostic significance of pulmonary lymphangioleiomyomatosis histologic score. Am J Surg Pathol 2001; 25: 479-484.

Avila NA, Kelly JA, Dwyer AJ, et al. Lymphangioleiomyomatosis: correlation of qualitative and quantitative thin-section CT with pulmonary function tests and assessment of dependence on pleurodesis. Radiology 2002; 223: 189-197.

Paciocco G, Uslenghi E, Bianchi A, et al. Diffuse cystic lung diseases: correlation between radiologic and functional status. Chest 2004; 125: 135-142.

Baldi BG, Freitas CS, Araujo MS, et al. Clinical course and characterisation of lymphangioleiomyomatosis in a Brazilian reference centre. Sarcoidosis Vasc Diffuse Lung Dis 2014; 31: 129-135.

McCormack FX, Inoue Y, Moss J, et al. Efficacy and safety of sirolimus in lymphangioleiomyomatosis. N Engl J Med 2011; 364: 1595-1606.

Crausman RS, Jennings CA, Mortenson RL, et al. Lymphangioleiomyomatosis: the pathophysiology of diminished exercise capacity. Am J Respir Crit Care Med 1996; 153: 1368-1376.

Baldi BG, de Albuquerque AL, Pimenta SP, et al. Exercise performance and dynamic hyperinflation in lymphangioleiomyomatosis. Am J Respir Crit Care Med 2012; 186: 341-348.

Baldi BG, de Albuquerque AL, Pimenta SP, et al. A pilot study assessing the effect of bronchodilator on dynamic hyperinflation in LAM. Respir Med 2013; 107: 1773-1780.

Bahmer T, Watz H, Waschki B, et al. Reduced physical activity in lymphangioleiomyomatosis compared with COPD and healthy controls: disease-specific impact and clinical correlates. Thorax 2016; 71: 662-663.

Krymskaya VP, Goncharova EA. PI3K/mTORC1 activation in hamartoma syndromes: therapeutic prospects. Cell Cycle 2009; 8: 403-413.

Bissler JJ, McCormack FX, Young LR, et al. Sirolimus for angiomyolipoma in tuberous sclerosis complex or lymphangioleiomyomatosis. N Engl J Med 2008; 358: 140-151.

Taveira-DaSilva AM, Hathaway O, Stylianou M, et al. Changes in lung function and chylous effusions in patients with lymphangioleiomyomatosis treated with sirolimus. Ann Intern Med 2011; 154: 797-805.

Yao J, Taveira-DaSilva AM, Jones AM, et al. Sustained effects of sirolimus on lung function and cystic lung lesions in lymphangioleiomyomatosis. Am J Respir Crit Care Med 2014; 190: 1273-1282.

Ando $\mathrm{K}$, Kurihara $\mathrm{M}$, Kataoka $\mathrm{H}$, et al. Efficacy and safety of low-dose sirolimus for treatment of lymphangioleiomyomatosis. Respir Investig 2013; 51: 175-183.

Franz DN, Belousova E, Sparagana S, et al. Efficacy and safety of everolimus for subependymal giant cell astrocytomas associated with tuberous sclerosis complex (EXIST-1): a multicentre, randomised, placebo-controlled phase 3 trial. Lancet 2013; 381: 125-132.

Bissler JJ, Kingswood JC, Radzikowska E, et al. Everolimus for angiomyolipoma associated with tuberous sclerosis complex or sporadic lymphangioleiomyomatosis (EXIST-2): a multicentre, randomised, double-blind, placebo-controlled trial. Lancet 2013; 381: 817-824.

Goldberg HJ, Harari S, Cottin V, et al. Everolimus for the treatment of lymphangioleiomyomatosis: a phase II study. Eur Respir J 2015; 46: 783-794.

Adamson D, Heinrichs WL, Raybin DM, et al. Successful treatment of pulmonary lymphangiomyomatosis with oophorectomy and progesterone. Am Rev Respir Dis 1985; 132: 916-921.

Clemm C, Jehn U, Wolf-Hornung B, et al. Lymphangiomyomatosis: a report of three cases treated with tamoxifen. Klin Wochenschr 1987; 65: 391-393.

Johnson SR, Tattersfield AE. Decline in lung function in lymphangioleiomyomatosis: relation to menopause and progesterone treatment. Am J Respir Crit Care Med 1999; 160: 628-633.

Taveira-DaSilva AM, Stylianou MP, Hedin CJ, et al. Decline in lung function in patients with lymphangioleiomyomatosis treated with or without progesterone. Chest 2004; 126: 1867-1874.

Harari S, Cassandro R, Chiodini I, et al. Effect of a gonadotropin-releasing hormone analogue on lung function in lymphangioleiomyomatosis. Chest 2008; 133: 448-454.

Baldi BG, Medeiros Junior P, Pimenta SP, et al. Evolution of pulmonary function after treatment with goserelin in patients with lymphangioleiomyomatosis. J Bras Pneumol 2011; 37: 375-379.

Pimenta SP, Baldi BG, Acencio MM, et al. Doxycycline use in patients with lymphangioleiomyomatosis: safety and efficacy in metalloproteinase blockade. J Bras Pneumol 2011; 37: 424-430.

Baldi BG, Ribeiro Carvalho CR. Doxycycline in lymphangioleiomyomatosis: not all questions are answered. Eur Respir J 2014; 43: 1536-1537.

Parkhitko A, Myachina F, Morrison TA, et al. Tumorigenesis in tuberous sclerosis complex is autophagy and p62/sequestosome 1 (SQSTM1)-dependent. Proc Natl Acad Sci USA 2011; 108: 12455-12460. 
81 Goncharova EA, Goncharova DA, Li H, et al. mTORC2 is required for proliferation and survival of TSC2-null cells. Mol Cell Biol 2011; 31: 2484-2498.

82 Taveira-DaSilva AM, Jones AM, Julien-Williams PJ, et al. Retrospective review of combined sirolimus and simvastatin therapy in lymphangioleiomyomatosis. Chest 2015; 147: 180-187.

83 Tyryshkin A, Bhattacharya A, Eissa NT. SRC kinase is a novel therapeutic target in lymphangioleiomyomatosis. Cancer Res 2014; 74: 1996-2005.

84 Govindarajan B, Brat DJ, Csete M, et al. Transgenic expression of dominant negative tuberin through a strong constitutive promoter results in a tissue-specific tuberous sclerosis phenotype in the skin and brain. J Biol Chem 2005; 280: 5870-5874.

85 Emilie JF, Abla O, Freitag S, et al. Revised classification of histiocytosis and neoplasms of macrophage-dendritic cell lineages. Blood 2016; 127: 2673-2681.

86 Vassallo R, Ryu JH, Schroeder DR, et al. Clinical outcomes of pulmonary Langerhans'-cell histiocytosis in adults. $N$ Engl J Med 2002; 346: 484-490.

87 Tazi A, Bonay M, Bergeron A, et al. Role of granulocyte-macrophage colony stimulating factor (GM-CSF) in the pathogenesis of adult pulmonary histiocytosis X. Thorax 1996; 51: 611-614.

88 Demedts IK, Bracke KR, Van Pottelberge G, et al. Accumulation of dendritic cells and increased CCL20 levels in the airways of patients with chronic obstructive pulmonary disease. Am J Respir Crit Care Med 2007; 175: 998-1005.

89 Tazi A, Moreau J, Bergeron A, et al. Evidence that Langerhans cells in adult pulmonary Langerhans cell histiocytosis are mature dendritic cells: importance of the cytokine microenvironment. J Immunol 1999; 163 : 3511-3515.

90 Colby TV, Lombard C. Histiocytosis X in the lung. Hum Pathol 1983; 14: 847-856.

91 Tazi A, Bonay M, Grandsaigne M, et al. Surface phenotype of Langerhans cells and lymphocytes in granulomatous lesions from patients with pulmonary histiocytosis X. Am Rev Respir Dis 1993; 147: $1531-1536$.

92 Hayashi T, Rush WL, Travis WD, et al. Immunohistochemical study of matrix metalloproteinases and their tissue inhibitors in pulmonary Langerhans' cell granulomatosis. Arch Pathol Lab Med 1997; 121: 930-937.

93 Coury F, Annels N, Rivollier A, et al. Langerhans cell histiocytosis reveals a new IL-17A-dependent pathway of dendritic cell fusion. Nat Med 2008; 14: 81-87.

94 Hutter C, Kauer M, Simonitsch-Klupp I, et al. Notch is active in Langerhans cell histiocytosis and confers pathognomonic features on dendritic cells. Blood 2012; 120: 5199-5208.

95 Brabencova E, Tazi A, Lorenzato M, et al. Langerhans cells in Langerhans cell granulomatosis are not actively proliferating cells. Am J Pathol 1998; 152: 1143-1149.

96 Yousem SA, Colby TV, Chen YY, et al. Pulmonary Langerhans' cell histiocytosis: molecular analysis of clonality. Am J Surg Pathol 2001; 25: 630-636.

97 Willman CL, Busque L, Griffith BB, et al. Langerhans'-cell histiocytosis (histiocytosis X)-a clonal proliferative disease. N Engl J Med 1994; 331: 154-160.

98 Badalian-Very G, Vergilio JA, Degar BA, et al. Recurrent BRAF mutations in Langerhans' cell histiocytosis. Blood 2010; 116: 1919-1923.

99 Satoh T, Smith A, Sarde A, et al. B-RAF mutant alleles associated with Langerhans cell histiocytosis, a granulomatous pediatric disease. PLoS One 2012; 7: e33891.

100 Sahm F, Capper D, Preusser M, et al. BRAFV600E mutant protein is expressed in cells of variable maturation in Langerhans cell histiocytosis. Blood 2012; 120: e28-e34.

101 Hervier B, Haroche J, Arnaud L, et al. Association of both Langerhans cell histiocytosis and Erdheim-Chester disease linked to the BRAFV600E mutation. Blood 2014; 124: 1119-1126.

102 Roden $\mathrm{AC}, \mathrm{Hu} \mathrm{X}$, Kip S, et al. BRAFV600E expression in Langerhans cell histiocytosis: clinical and immunohistochemical study on 25 pulmonary and 54 extrapulmonary cases. Am J Surg Pathol 2014; 38: 548-551.

103 Haroche J, Charlotte F, Arnaud L, et al. High prevalence of BRAF V600E mutations in Erdheim-Chester disease but not in other non-Langerhans cell histiocytoses. Blood 2012; 120: 2700-2703.

104 Fiskus W, Mitsiades N. B-raf inhibition in the clinic: present and future. Annu Rev Med 2016; 67: 29-439.

105 Chakraborty R, Hampton OA, Shen X, et al. Mutually exclusive recurrent somatic mutations in MAP2K1 and BRAF support a central role for ERK activation in LCH pathogenesis. Blood 2014; 124: 3007-3015.

106 Nelson DS, van Halteren A, Quispel WT, et al. MAP2K1 and MAP3K1 mutations in Langerhans cell histiocytosis. Genes Chromosomes Cancer 2015; 54: 361-368.

107 Mourah S, How-Kit A, Meignin V, et al. Recurrent NRAS mutations in pulmonary Langerhans cell histiocytosis. Eur Respir J 2016; 47: 1785-1796.

108 Berres ML, Lim KP, Peters T, et al. BRAF-V600E expression in precursor versus differentiated dendritic cells defines clinically distinct LCH risk groups. J Exp Med 2015; 212: 281.

109 Héritier S, Emile JF, Barkaoui MA, et al. BRAF mutation correlates with high-risk Langerhans cell histiocytosis and increased resistance to first-line therapy. J Clin Oncol 2016; 34: 3023-3030.

110 Bracke KR, D'Hulst A I, Maes T, et al. Cigarette smoke-induced pulmonary inflammation and emphysema are attenuated in CCR6-deficient mice. J Immunol 2006; 177: 4350-4359.

111 Churg A, Tai H, Coulthard T, et al. Cigarette smoke drives small airway remodeling by induction of growth factors in the airway wall. Am J Respir Crit Care Med 2006; 174: 1327-1334.

112 Hashimoto M, Yanagisawa H, Minagawa S, et al. TGF-beta-dependent dendritic cell chemokinesis in murine models of airway disease. J Immunol 2015; 195: 1182-1190.

113 Prasse A, Stahl M, Schulz G, et al. Essential role of osteopontin in smoking-related interstitial lung diseases. Am J Pathol 2009; 174: 1683-1691.

114 Torre O, Harari S. The diagnosis of cystic lung diseases: a role for bronchoalveolar lavage and transbronchial biopsy? Respir Med 2010; 104: S81-S85.

115 Hance AJ, Basset F, Saumon G, et al. Smoking and interstitial lung disease. The effect of cigarette smoking on incidence of pulmonary histiocytosis X and sarcoidosis. Ann N Y Acad Sci 1986; 465: 643-656. 

diagnosis of pulmonary histiocytosis X. Lung 1991; 169: 305-309. lavage of patients with pulmonary Langerhans cell, sarcoidosis and idiopathic pulmonary fibrosis. Virchows Arch 2004; 444: 171-174.

118 Harari S, Torre O, Cassandro R, et al. Bronchoscopic diagnosis of Langerhans cell histiocytosis and lymphangioleiomyomatosis. Respir Med 2012; 106: 1286-1292.

119 Fruchter O, Fridel L, El Raouf BA, et al. Histological diagnosis of interstitial lung diseases by cryo-transbronchial biopsy. Respirology 2014; 19: 683-688.

120 Hyman DM, Diamond FL, Vibat CR, et al. Prospective blinded study of BRAFV600E mutation detection in cell-free DNA of patients with systemic histiocytotic disorders. Cancer Discov 2015; 5: 64-71.

121 Janku F, Vibat CR, Kosco K, et al. BRAF V600E mutations in urine and plasma cell-free DNA from patients with Erheim-Chester disease. Oncotarget 2014; 5: 3607-3610.

122 Obert J, Vercellino L, van Der Gucht A, et al. (18)F-fluorodeoxyglucose positron emission tomography-computed tomography in the management of adult multisystem Langerhans cell histiocytosis. Eur $J$ Nucl Med Mol Imaging 2017; 44: 598-610.

123 Tazi A, de Margerie C, Naccache JM, et al. The natural history of adult pulmonary Langerhans cell histiocytosis: a prospective multicentre study. Orphanet J Rare Dis 2015; 10: 30.

124 Tazi A, Marc K, Dominique S, et al. Serial computed tomography and lung function testing in pulmonary Langerhans' cell histiocytosis. Eur Respir J 2012; 40: 905-912.

125 Crausman RS, Jennings CA, Tuder RM, et al. Pulmonary histiocytosis X: pulmonary function and exercise pathophysiology. Am J Respir Crit Care Med 1996; 153: 426-435.

126 Rolland-Debord C, Fry S, Giovannelli J, et al. Physiologic determinants of exercise capacity in pulmonary Langerhans cell histiocytosis: a multidimensional analysis. PLoS One 2017; 12: e0170035.

127 Ninaber M, Dik H, Peters E. Complete pathological resolution of pulmonary Langerhans cell histiocytosis. Respirol Case Rep 2014; 2: 76-78.

128 Wolters PJ, Elicker BM. Subacute onset of pulmonary Langerhans cell histiocytosis with resolution after smoking cessation. Am J Respir Crit Care Med 2014; 190: e64.

129 Schönfeld N, Frank W, Wenig S, et al. Clinical and radiologic features, lung function and therapeutic results in pulmonary histiocytosis X. Respiration 1993; 60: 38-44.

130 Vassallo R, Ryu JH, Colby TV, et al. Pulmonary Langerhans'-cell histiocytosis. N Engl J Med 2000; 342: 1969-1978.

131 Travis WD, Borok Z, Roum JH, et al. Pulmonary Langerhans cell granulomatosis (histiocytosis X). A clinicopathologic study of 48 cases. Am J Surg Pathol 1993; 17: 971-986.

132 Elia D, Torre O, Cassandro R, et al. Pulmonary Langerhans cell histiocytosis: a comprehensive analysis of 40 patients and literature review. Eur J Intern Med 2015; 26: 351-356.

133 Lazor R, Etienne-Mastroianni B, Khouatra C, et al. Progressive diffuse pulmonary Langerhans cell histiocytosis improved by cladribine chemotherapy. Thorax 2009; 64: 274-275.

134 Grobost V, Khouatra C, Lazor R, et al. Effectiveness of cladribine therapy in patients with pulmonary Langerhans cell histiocytosis. Orphanet J Rare Dis 2014; 9: 191.

135 Lorillon G, Bergeron A, Detourmignies L, et al. Cladribine is effective against cystic pulmonary langerhans cell histiocytosis. Am J Respir Crit Care Med 2012; 186: 930-932.

136 Dietrich S, Glimm H, Andrulis M, et al. BRAF inhibition in refractory hairy-cell leukemia. $N$ Engl J Med 2012; 366: 2038-2040.

137 Haroche J, Cohen-Aubart F, Emile JF, et al. Dramatic efficacy of vemurafenib in both multisystemic and refractory Erdheim-Chester disease and Langerhans cell histiocytosis harboring the BRAF V600E mutation. Blood 2013; 121: 1495-1500.

138 Hyman DM, Puzanov I, Subbiah V, et al. Vemurafenib in multiple nonmelanoma cancers with BRAF V600 mutations. N Engl J Med 2015; 373: 726-736. 